\title{
FRMD3 gene: its role in diabetic kidney disease. A narrative review
}

\author{
Marjoriê Piuco Buffon 1,2,3, Denise Alves Sortica ${ }^{1,2,3}$, Fernando Gerchman 1,2,3, Daisy Crispim 1,2 \\ and Luís Henrique Canani ${ }^{1,2,3^{*}}$
}

\begin{abstract}
Diabetic kidney disease (DKD) is a chronic complication of diabetes mellitus, which is considered a worldwide epidemic. Several studies have been developed in order to elucidate possible genetic factors involved in this disease. The FRMD3 gene, a strong candidate selected from genome wide association studies (GWAS), encodes the structural protein $4.1 \mathrm{O}$ involved in maintaining cell shape and integrity. Some single nucleotide polymorphisms (SNPs) located in FRMD3 have been associated with DKD in different ethnicities. However, despite these findings, the matter is still controversial. The aim of this narrative review is to summarize the evidence regarding the role of FRMD3 in DKD.
\end{abstract}

\section{Background}

Diabetes mellitus (DM) is a complex and chronic illness involving a state of hyperglycemia [1]. Depending on the intensity and duration of exposure to hyperglycemia, structural lesions may occur in the vascular endothelium and nervous tissue, causing damage and dysfunction in multiple organs and tissues, leading to chronic complications [2]. One such complication is diabetic kidney disease (DKD), in which there is increased urine excretion of proteins, predominantly albumin [3]. The precise mechanism that determines which patients with DM would or would not progress to renal failure and dialysis has yet to be elucidated. A great effort has been devoted to the study of candidate genes related to DKD development and progression.

\section{Diabetic kidney disease}

DKD, which was initially described as a glomerular disease characterized by proteinuria, seems to be much more than that. Chronic kidney disease (CKD) is defined as renal damage resulting from structural or functional abnormalities of the kidneys, or glomerular filtration

\footnotetext{
*Correspondence: luishenriquecanani@gmail.com

${ }^{1}$ Endocrine Division, Hospital de Clínicas de Porto Alegre, Federal University of Rio Grande do Sul, Rua Ramiro Barcelos 2350, prédio 12, $4^{\circ}$ andar, Porto Alegre, RS 90035-003, Brazil

Full list of author information is available at the end of the article
}

rate $($ GFR $)<60 \mathrm{ml} / \mathrm{min} / 1.73 \mathrm{~m}^{2}$ with or without kidney damage over a period of time equal to or greater than 3 months [4]. DKD affects around 25-30 \% of individuals with DM and is responsible for over a quarter of new cases of end-stage renal disease (ESRD) [5, 6]. In $25 \%$ of patients with DM, increased urinary albumin excretion (UAE) is observed [7]. Furthermore, low GFR has also been reported in a substantial proportion of normoalbuminuric subjects [7-10]. As a result, since 2006 the American Diabetes Association (ADA) has recommended DKD assessment based on UAE and estimated GFR (eGFR) [11, 12]. More recently, ADA has suggested that albuminuria must be classified as normal UAE or increased UAE [12], instead using the term microalbuminuria $[13,14]$.

Despite the high prevalence and severity of DKD, not all individuals with DM will develop this disease. The cumulative incidence of persistent albuminuria (microalbuminuria) in patients with type 1 diabetes mellitus (T1DM) has been reported from $12.6 \%$ over 7.3 years according to The European Diabetes Prospective Complications Study Group (EURODIAB) [15] to $33 \%$ in an 18-year study carried out in Denmark [16]. It seems that T1DM patients who do not develop DKD 10-15 years after diagnosis are protected from this complication [17]. Furthermore, some subjects with elevated albuminuria will progress to a more severe albumin profile and GFR loss, while others will remain stable or even return 
to normoalbuminuria $[18,19]$. Thus, it is believed that the presence of risk factors such as hyperglycemia and hypertension will lead to DKD in genetically predisposed individuals.

\section{The genetics of diabetic kidney disease}

Familial clustering of DKD, a multifactorial disease, has been reported in several studies, supporting the hypothesis that genetic factors are involved in its pathogenesis $[20,21]$. However, all the efforts to identify a gene with a major effect have been disappointing, possibly because several genes are involved, acting synergistically or additively [22]. For instance, some genes might be related to increased albuminuria, and others to GFR decline [23, 24].

Pezzolesi et al. [25] conducted a genome wide association study (GWAS) in Caucasians with T1DM and found 13 SNPs (single nucleotide polymorphisms) associated with DKD. The most significant associations were identified in variants located near genes from four chromosomal regions: CHN2/CPVL on chromosome 7, FRMD3 on chromosome 9, CARS on chromosome 11, and a locus near the IRS2 on chromosome 13. Among those, the strongest association was near the FRMD3 gene (4.1 protein ezrin, radixin, moesin [FERM] domain containing 3). Nevertheless, Maeda et al. [26] analyzed polymorphic variants of this gene [25] in Japanese with type 2 diabetes mellitus (T2DM) and did not find any association with DKD.

Regardless of extensive evidence of genetic susceptibility to DKD, the identification of susceptibility genes and their variants has had limited success [27, 28]. Mooyart et al. [29] conducted a meta-analysis of genetic association studies focusing on DKD and found that 21 genetic variants were significantly associated with DKD [29], two of them in the FRMD3 gene. Other variants were in or near the following genes: $A C E, A K R 1 B 1, A P O C 1, A P O E$, EPO, NOS3, HSPG2, VEGFA, CARS, UNC13B, CPVL, $C H N 2$, GREM1, and others. Additional variants were detected in subgroup analyses: ELMO1 (Asians), CCR5 (Asians), and CNDP1 (T2DM). However, these associations were not confirmed by others [30].

The inconsistencies in the results of genetic association studies in complex diseases could be due to small sample sizes or incorrect associations conducting to false or spurious positive results [31-34]. Therefore, independent replication of positive associations remains essential to avoid associations by chance.

\section{FRMD3 gene}

The FRMD3 (ID: 257019) is located on chromosome 9, band q21.32. It has 21 exons spanning 2,282 base pairs (http://www.ncbi.nlm.nih.gov/gene/257019) (Fig. 1). In addition, 7 different mRNA sequence splice variants for the FRMD3 gene are also shown in Fig. 1.

FRMD3 encodes protein $4.1 \mathrm{O}$, a structural protein that is part of the protein 4.1 family [35]. Members of this family act as cytoskeletal proteins, maintaining cell shape and integrity in a variety of cell types including rat nephron cells [36, 37]. However, the role of protein $4.1 \mathrm{O}$ has not yet been elucidated [38]. It contains a FERM domain, which contributes to cell integrity by interacting with transmembrane proteins and actin filaments $[38,39]$. FRMD3 is detected in different tissues according to the Nephromine database (Fig. 2). Studies also have reported FRMD3 expression in adult ovaries, fetal skeletal muscle, brain, thymus, and human podocytes [35]. In addition, FRMD3 expression seems to be decreased in a DKD mouse model as compared to non-diabetic mouse kidneys (Fig. 3a). FRMD3 is differentially expressed in different regions of murine kidney, showing the highest level in glomeruli (Fig. 3b).

The 4.1 protein family comprises a group of proteins including 4.1R, 4.1G (general type), 4.1B (brain type), and $4.1 \mathrm{~N}$ (neuron type) [40]. Erythrocyte protein 4.1 (4.1R) is a multifunctional protein essential for maintaining erythrocyte shape, mechanical properties of the membrane, deformability, and stability through interactions with the spectrin and actin skeleton network [40]. Figure 4 represents different domains of the FRMD3 protein. The FERM domain [38] is an N-terminal 30-kDa domain containing binding sites for cytoplasmatic tails of integral membrane proteins such as band 3 (integral membrane protein involved in spectrin-actin interaction) [41, 42], glycophorin C (erythroid membrane proteins) [43], CD44 (transmembrane glycoprotein found in erythroid as well as non-erythroid cells) [44], p55 (abundantly palmitoylated phosphoprotein of the erythroid membrane) [43] and calmodulin (a highly conserved calcium-binding protein, ubiquitously distributed in eukaryotic cells, known to affect a plethora of biological functions) [40]. An internal 8-10 kDa domain contains the spectrin-actin binding activity that is necessary for membrane stability [45], and the $22-24 \mathrm{kDa} \mathrm{C}$-terminal domain has been reported to bind immunophilin FKBP13 (membraneassociated protein thought to function as an endoplasmic reticulum chaperone) [46] and nuclear mitotic apparatus protein (NuMA) [47].

FERM domain proteins have been implicated in nephron function. Some of these proteins were described as important in the composition of specialized cell-cell adhesion complexes. These complexes called slit-diaphragms that form between podocyte foot processes surrounding glomerular blood vessels have an important 


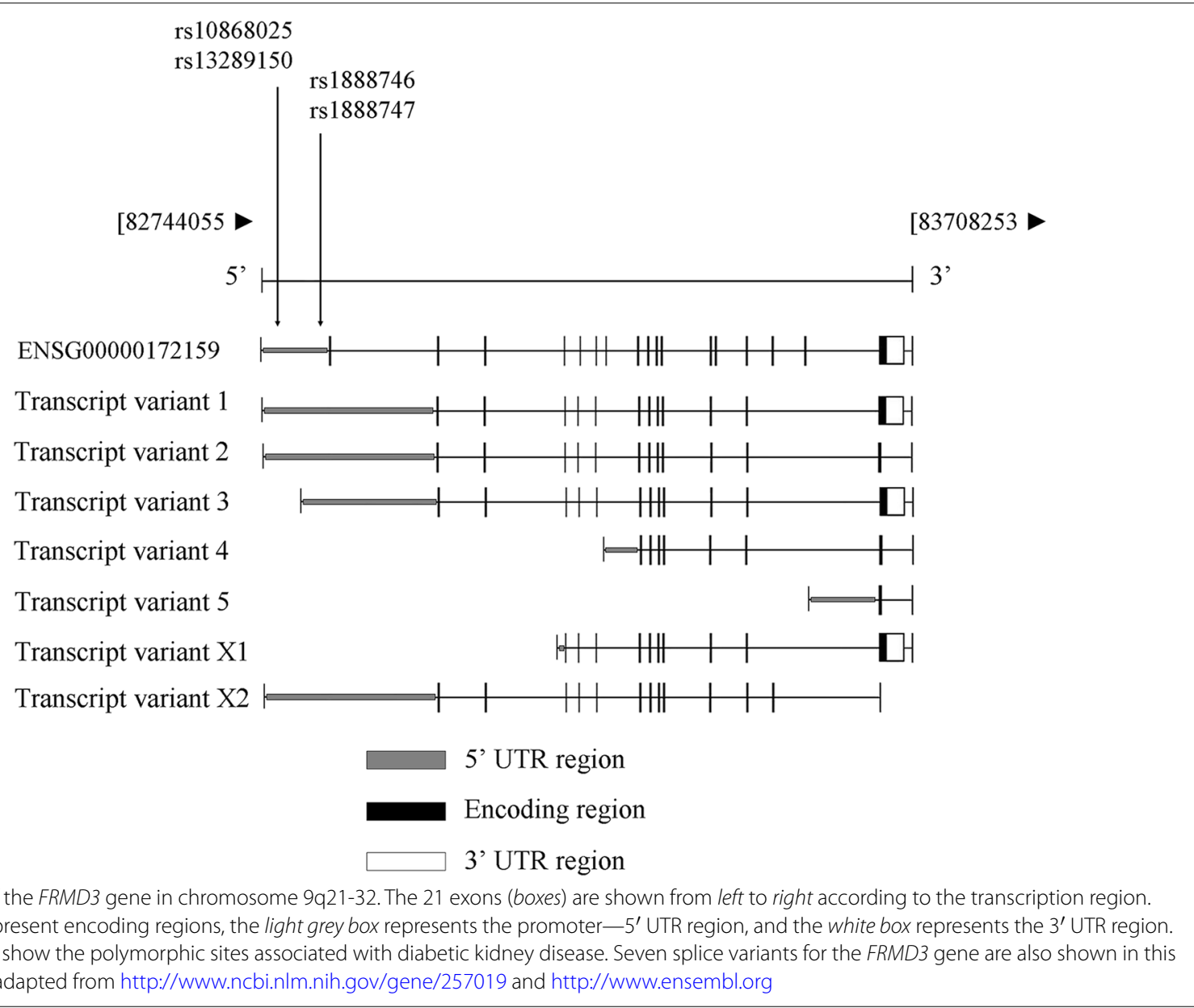

role in the function of podocytes, establishing the blood filtration barrier in the kidney glomerulus. A reduced expression of some FERM domain proteins in zebrafish, such as nephrin, podocin or band 4.1/FERM domain mosaic eyes resulted in loss of glomerular filtration discrimination and abnormal passage of high molecular weight substances into the glomerular filtrate [48]. Another FERM domain protein that has been recently related to nephron function is kindlin, an adaptor protein that contributes to renal tubulointerstitial fibrosis. This protein regulates renal tubular cell plasticity by activation of Ras and its downstream signaling pathway [49]. Therefore, it is possible that FRMD3 might have related functions in kidney.

In the study of Pezzolesi et al. [25], FRMD3 expression was increased in proximal renal tubular human cells. Expression data for FRMD3 and its co-expressed transcripts suggest that these genes are linked to early development of DKD [50]. Moreover, FRMD3 is predicted to interact with other genes, suggesting alternative pathways in which this gene might act (Fig. 5).
It has been hypothesized that the 9q21.32 locus contributes to glomerular injury early in the pathogenesis of DKD [51]. More recently, the rs1888747 risk allele was shown to generate a transcription factor binding site (TFBS) in a module that is shared by multiple members of the bone morphogenetic protein (BMP) signaling pathway, which has previously been implicated in the development of DKD [50, 52]. Regarding these findings, new pathways are being proposed to explain the role of FRMD3 in DKD physiopathology.

\section{Variants in the FRMD3 gene and diabetic kidney disease}

Research has been developed to investigate the association of variants in the FRMD3 gene and risk of DKD. The main variants studied so far are briefly described in Table 1. The polymorphisms rs942278, rs942280, rs942283, rs1535752, rs1535753, rs2378658, rs10867977 and rs10867977 are in strong linkage disequilibrium (LD) with each other. The Hapmap project does not show LD information for the rs1888746, rs1888747, rs10868025 and rs13289150 SNPs (http://hapmap.ncbi.nlm.nih.gov). 


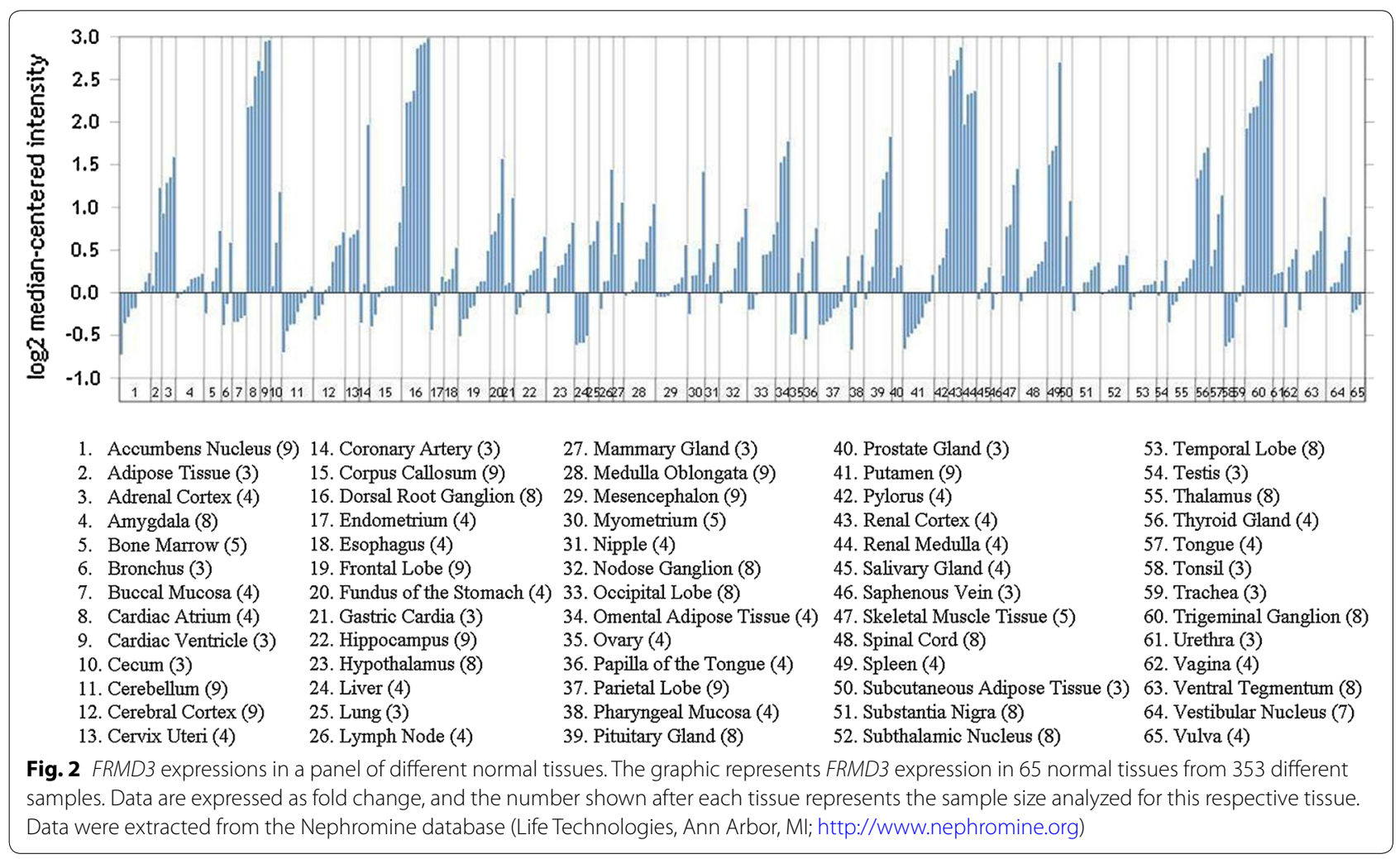

The first published study regarding variants in FRMD3 was a GWAS with T1DM patients from the GoKinD (Genetics of Kidneys in Diabetes) collection [25]. The SNP rs10868025 had the strongest association with DKD $\left(\mathrm{OR}=1.45, \mathrm{P}=5.0 \times 10^{-7}\right)$ [25]. This SNP involves a $G$ for A nucleotide substitution and is located in the long arm of chromosome 9 at position 85.4, near the $5^{\prime}$ end of FRMD3 [25]. The frequency of the risk allele was 0.66/0.56 (cases/controls) in the Joslin Diabetes Center study (JDC study) and 0.66/0.59 in the George Washington University study (GWU study) [25]. Two other FRMD3 SNPs associated with DKD in the GoKinD collection (rs1888746 and rs13289150) were also associated with the development of severe nephropathy in the DCCT/EDIC (Diabetes Control and Complications Trial/ Epidemiology of Diabetes Interventions and Complications) follow-up study [25].

In a meta-analysis, involving three studies including 1052 cases and 2057 controls, the rs10868025 SNP was associated with a lower risk of DKD in European T1DM subjects (OR 0.72 [95 \% CI 0.64-0.81]) [29], whereas in a study with T2DM subjects [26], no significant associations between the rs10868025 SNP and DKD were detected in four independent Japanese populations. The $\mathrm{G}$ allele frequency for cases vs. controls in the four populations studied was: 0.74 vs. $0.73,0.72$ vs. $0.73,0.67$ vs.
0.73 , and 0.70 vs. 0.73 ( $\mathrm{P}>0.25$ in all cases). The same findings were replicated in the Chinese population [53], for which no association between FRMD3 SNPs and DKD was observed $(\mathrm{P}=0.249)$.

The rs1888747 (C/G) SNP is intergenic, located on the long arm of chromosome 9 at position 85.3, near the promoter region of the gene [54]. In the study developed by Pezzolesi et al. [25], a relevant association of rs 1888747 SNP was found with DKD $\left(P=6.3 \times 10^{-7}\right)$ in Caucasians with T1DM. The frequency of the risk allele $(\mathrm{G})$ was $0.68 / 0.73$ for controls/cases in the GWU GoKinD and 0.66/0.74 for controls/cases in the JDC GoKinD [25]. These findings were strengthened by a meta-analysis including three studies analyzing the rs1888747 SNP in a total of 1052 cases and 2057 controls [29], which confirmed an association of rs1888747 SNP with DKD (OR 0.74 [95 \% CI 0.65-0.83]; $\mathrm{P}=0.602$ ) [29], primarily driven by the GoKinD cohort. However, in Japanese individuals with T2DM, no associations between rs1888747 SNP and DKD were demonstrated in four different groups [26]. The frequency of the $\mathrm{G}$ allele for cases/controls was $0.81 / 0.80,0.80 / 0.80,0.70 / 0.82$ and $0.77 / 0.81$ $(\mathrm{P}>0.05)$.

In 2011, Freedman et al. [55] identified that a potential interaction between FRMD3 and the APOL1 (apolipoprotein L1 gene) $-M Y H 9$ (non-muscle myosin heavy 


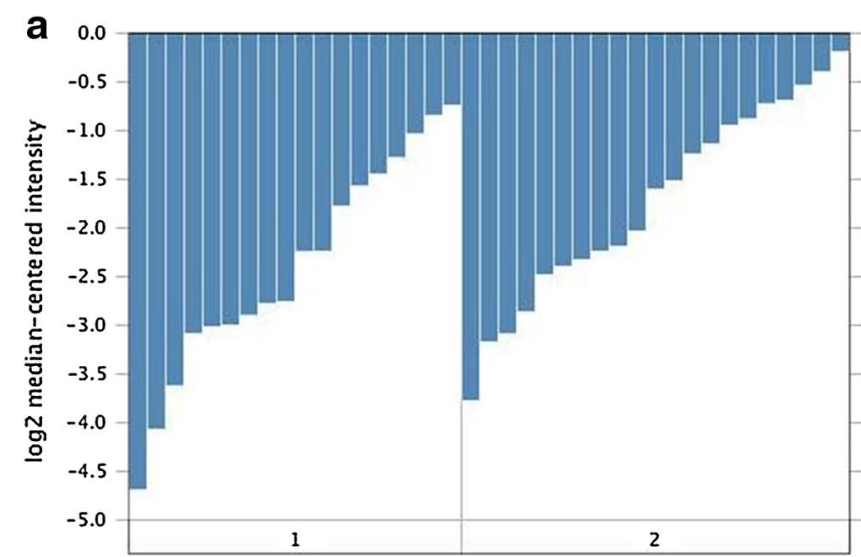

1. Non-Diabetic Mouse Kidney (18)

2. Diabetic Kidney Disease Mouse Model (21)

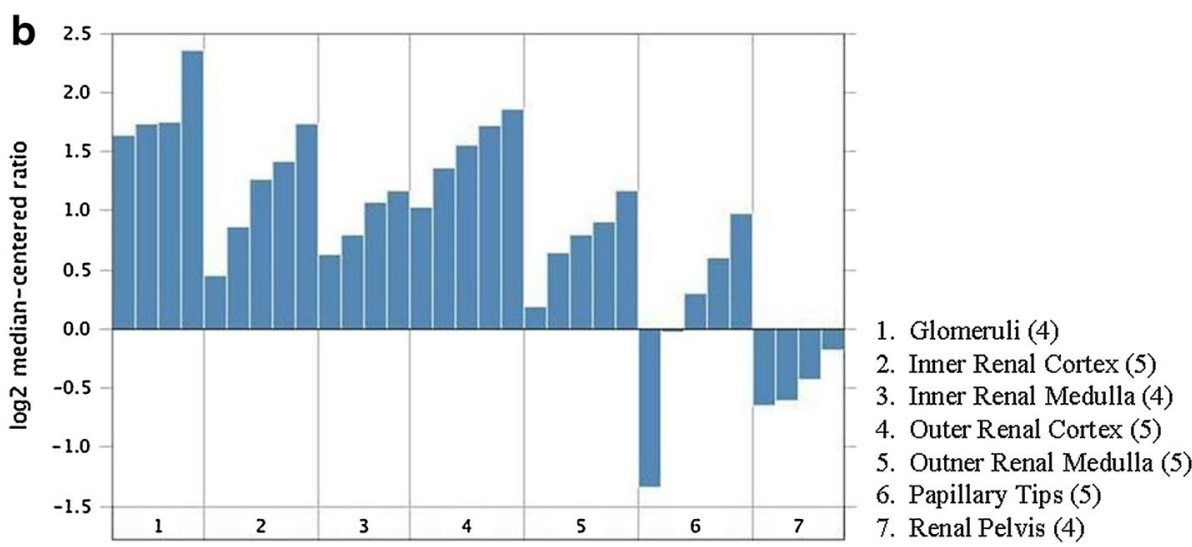

Fig. 3 FRMD3 expression in kidney. a FRMD3 expression in Hodgins mice according to the presence of diabetic kidney disease. The graphic represents mRNA expression from 39 kidney samples. b FRMD3 expression in a normal kidney from Higgins mice according to different kidney regions. The graphic represents mRNA expressions from 34 kidney samples. Data are expressed as fold change, and were extracted from the Nephromine database (Life Technologies, Ann Arbor, Ml; http://www.nephromine.org)

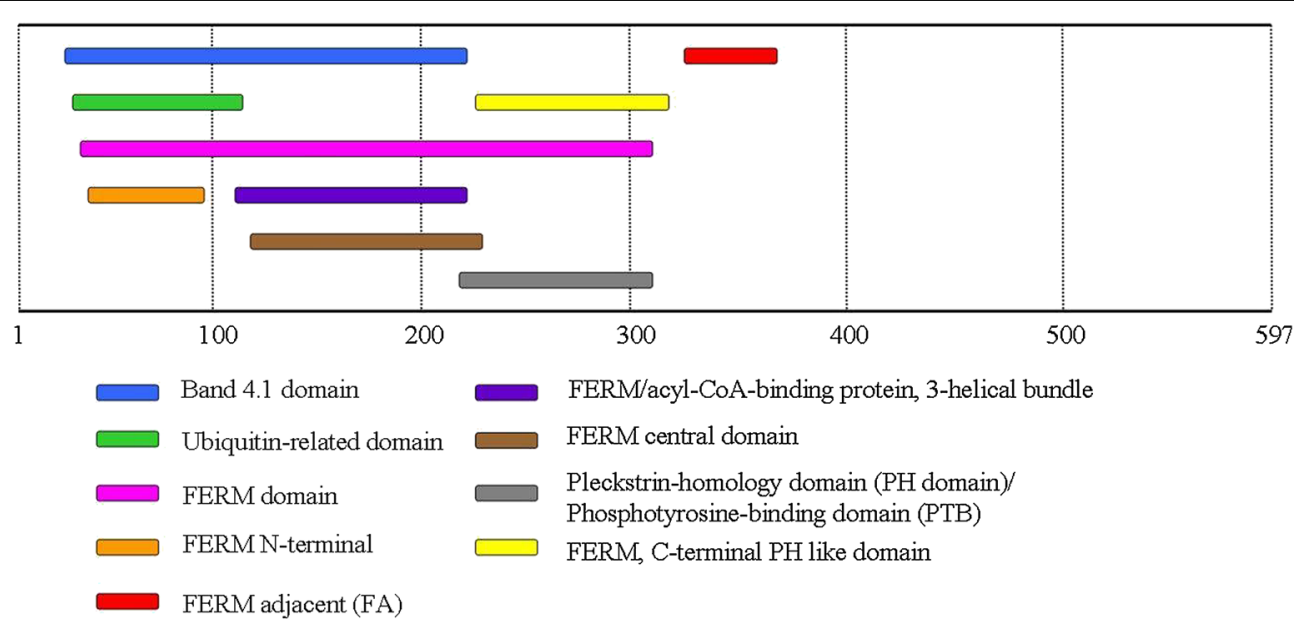

Fig. 4 Different domains of the FRMD3 protein. The various domains are depicted according to the specific length of each domain. The complete protein length is 597 amino acids. Figure adapted from http://www.ebi.ac.uk/interpro/protein/A2A2Y4 


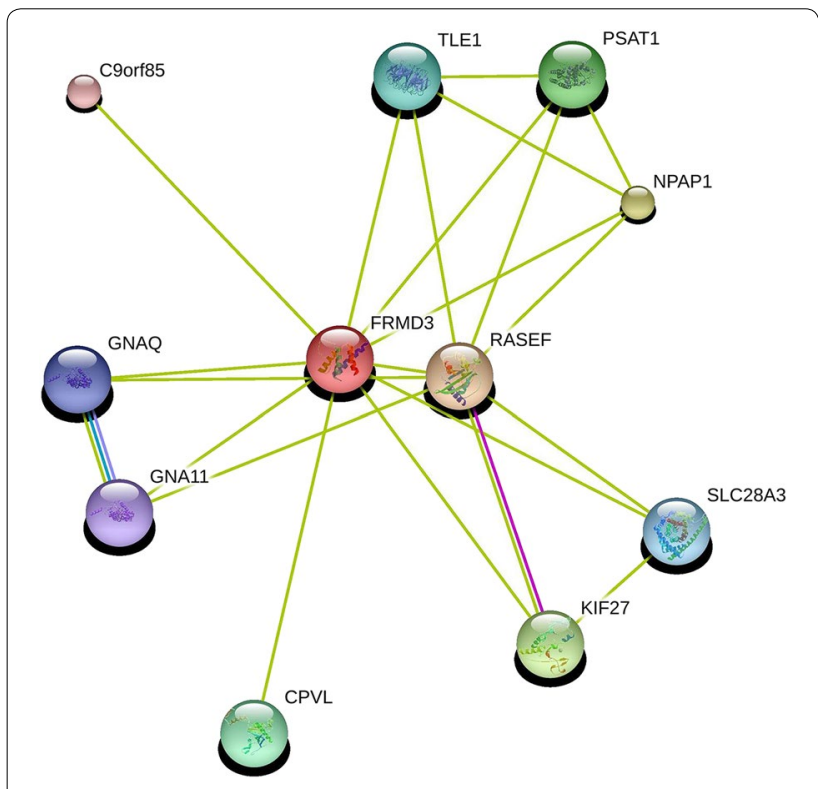

Fig. 5 FRMD3 protein interaction view networks in humans. The figure represents predicted interactions of FRMD3 with different proteins using medium confidence algorithms. Lines of different colors indicate that the respective interaction was predicted using more than one algorithm/tool. RASEF RAS and EF-hand domain containing, NPAP1 nuclear pore associated protein 1, KIF27 kinesin family member 27, PSAT1 phosphoserine aminotransferase 1, CPVL carboxypeptidase, vitellogenic-like, TLE1 transducin-like enhancer of split 1 (E(sp1) homolog, Drosophila), SLC28A3 solute carrier family 28 (sodium-coupled nucleoside transporter), member 3, GNAQ guanine nucleotide binding protein (G protein), q polypeptide, GNA11 guanine nucleotide binding protein (G protein), alpha 11 (Gq class), C9orf85 chromosome 9 open reading frame 85. Figure extracted from database Search Tool for the Retrieval of Interacting Genes/Proteins STRING.db (http://string-db.org/)

chain 9 gene) region on chromosome 22 contributes to DKD susceptibility in African Americans. Nevertheless, initially no association was found between FRMD3 SNPs (rs942280 and others, Table 1) and DKD before adjusting for variants on chromosome 20 . The results revealed an approximately 25-30 \% increase in DKD risk with multiple FRMD3 SNPs in subjects not homozygous for $M Y H 9$ risk haplotypes (or APOL1risk variants).

One year later, Williams et al. [30] formed the GEnetics of Nephropathy, an International Effort (GENIE) consortium, to examine reported genetic associations with DKD in T1DM previously observed in the GoKinD collection [25]. The samples were provided by the All Ireland-Warren 3-Genetics of Kidneys in Diabetes UK and Republic of Ireland (UK-ROI) collection and the Finnish DKD Study (FinnDiane). None of the analyzed FRMD3 polymorphisms were associated with DKD (rs1888747 [P $=0.77$ and 0.25 , UK-ROI and FinnDiane respectively]; rs1086805 [P $=0.52$ for UK-ROI and 0.25 for FinnDiane]) [30].
Further evidence of the role of FRMD3 in kidney disease came from the study of Park et al. [56]. In this study, the authors aimed to find candidate genetic determinants of renal function in 1007 individuals from 73 extended families of Mongolian origin [56]. The strongest associations found were with rs17400257 SNP $\left(\mathrm{P}=7.21 \times 10^{-9}\right)$ and rs6559725 SNP $\left(\mathrm{P}=9.12 \times 10^{-7}\right)$. The rs17400257 SNP is located $45 \mathrm{~kb}$ downstream of FRMD3, and rs6559725 SNP is located in the intronic region of FRMD3 [56].

After the initial findings in T1DM in 2009 [25], Pezzolesi et al. [51] proceeded to examine whether the SNPs at these susceptibility loci were associated with DKD in a T2DM Family Collection. The 9q21.32 locus was significantly associated with high microalbuminuria, proteinuria, and ESRD [51]. Among diabetic family members, rs1888747 SNP on chromosome 9q21.32 was associated with advanced nephropathy $(P=0.029)$. Furthermore, when the definition of DKD was expanded to include individuals with high microalbuminuria, the strength of the association improved significantly [51].

Martini et al. [50] proposed a transcriptional link that might explain how the rs1888747 SNP in FRMD3 influences transcriptional regulation within the bone morphogenetic protein (BMP)-signaling pathway. FRMD3 transcript levels decreased significantly with the progression of DKD $(\mathrm{P}<0.02)$. FRMD3 gene expression was studied by comparing renal biopsies in a group of 22 Pima Indians with T2DM and normal GFR and a cohort of seven participants with T2DM and CKD stage 3 [50]. Hierarchical clustering using the FRMD3 coexpressed transcripts detected two distinct clusters. In cluster 1 , presenting higher $\triangle \mathrm{ACR} /$ year ( $\Delta$ albuminto-creatinine ratio per year), gene expressions of seven out of the eight BMP pathway genes (BMPR2, CREB1, KRAS, MAP3K7, PRKAR2B, SMAD5, and XIAP) were lower than the expressions of these genes in cluster 2 . These findings suggest a common molecular mechanism responsible for the coregulation of FRMD3 and several BMP pathway members [50]. Additionally, in silico comparison of sequence variants of the risk allele identified a potential homeodomain factor (HOMF) transcription factor binding site (TFBS) covering the SNP position [50]. The rs1888747 SNP affects protein binding, suggesting the generation of a TFBS by this particular SNP [50]. However, the mechanism mediating the connection between FRMD3 and BMP pathway members is still unknown, and no data are available at protein, RNA, or microRNA levels to elucidate this association [50]. It should be noted that Palmer and Freedman [54] suggested that the framework proposed by Martini et al. [50] is limited to genes with known or predicted functional roles. 
Table 1 FRMD3 variants studied in the context of diabetic kidney disease

\begin{tabular}{|c|c|c|c|c|c|c|c|}
\hline Variant & Reference & Ethnicity & Sample description & $\begin{array}{l}\text { Chromossome } 9^{a} \\
\text { position }\end{array}$ & Risk allele & $P$ value & Odds ratio $(95 \% \mathrm{Cl})$ \\
\hline rs942278 & Freedman et al. [55] & African-American & $\begin{array}{l}966 \text { cases (T2DM-DKD) } \\
1032 \text { controls (Non-DM, } \\
\text { non DKD) }\end{array}$ & 85906066 & $\mathrm{~T}$ & 0.0023 & $1.30(1.11-1.53)$ \\
\hline rs942280 & & & & 85905861 & G & 0.00070 & $1.28(1.09-1.51)$ \\
\hline rs942283 & & & & 85905666 & C & 0.0014 & $1.25(1.07-1.47)$ \\
\hline rs1535752 & & & & 85905253 & $\mathrm{~T}$ & 0.013 & $1.27(1.03-1.57)$ \\
\hline rs1535753 & & & & 85905060 & $\mathrm{~T}$ & 0.0024 & $1.24(1.06-1.46)$ \\
\hline rs2378658 & & & & 85904778 & C & 0.0040 & $1.25(1.06-1.46)$ \\
\hline rs10867977 & & & & 85907516 & G & 0.022 & $1.31(1.06-1.62)$ \\
\hline \multirow[t]{2}{*}{ rs1888746 } & Hu et al. [53] & Chinese & $\begin{array}{l}622 \text { cases (378 T2DM- } \\
\text { DKD and } 244 \text { DKD } \\
\text { and retinopathy) } \\
280 \text { controls ( }>10 \text { years } \\
\text { T2DM) }\end{array}$ & 86155392 & C & 0.66 & $0.93(0.60-1.38)$ \\
\hline & Pezzolesi et al. [25] & Caucasian & $\begin{array}{l}820 \text { cases ( } 284 \text { - pro- } \\
\text { teinuria and } 536- \\
\text { ESRD) } \\
885 \text { controls (T1DM) }\end{array}$ & 86155392 & C & 0.02 & $N A^{b}$ \\
\hline \multirow[t]{8}{*}{ rs1888747 } & Maeda et al. [26] & Japanese & $\begin{array}{l}754 \text { cases (T2DM- DKD } \\
\text { and retinopathy) } \\
\text { and } 558 \text { controls } \\
\text { (T2DM_-only retin- } \\
\text { opathy) }\end{array}$ & 86155551 & G & 0.10 & $1.24(0.96-1.61)$ \\
\hline & & & $\begin{array}{l}449 \text { cases (T2DM_DKD } \\
\text { and retinopathy) and } \\
965 \text { controls (T2DM- } \\
\text { only retinopathy) }\end{array}$ & & & 0.84 & $1.02(0.83-1.26)$ \\
\hline & & & $\begin{array}{l}32 \text { cases (T2DM- } \\
\text { microalbuminuria } \\
\text { progressed to overt } \\
\text { proteinuria) and } 168 \\
\text { controls (T2DM- } \\
\text { microalbuminuria) }\end{array}$ & & & 0.004 & $0.28(0.12-0.67)$ \\
\hline & & & $\begin{array}{l}300 \text { cases (T2DM-DKD) } \\
\text { and } 224 \text { controls } \\
\text { (normoalbuminuria } \\
\text { and }>10 \text { years T2DM) }\end{array}$ & & & 0.43 & $0.87(0.61-1.23)$ \\
\hline & Pezzolesi et al. [25] & Caucasian & & & & 0.00000067 & $1.45(1.25-1.67)$ \\
\hline & Williams et al. [30] & Caucasian & $\begin{array}{l}\text { UK_ROI: } 903 \text { cases } \\
\text { (DKD, retinopathy } \\
\text { and ESRD) and } 1001 \\
\text { controls (T1DM) } \\
\text { FinnDiane: } 1289 \text { cases } \\
\text { (ESRD and macroal- } \\
\text { buminuria) and } 1577 \\
\text { controls (normoalbu- } \\
\text { minuria) } \\
\text { Reanalysis of US GoKind } \\
\text { data: } 905 \text { cases (DKD) } \\
\text { and } 898 \text { controls } \\
\text { (T1DM) }\end{array}$ & & & 0.24 & $1.06(0.96-1.17)$ \\
\hline & Pezzolesi et al. [58] & Caucasian & $\begin{array}{l}743 \text { cases (T2DM- } 427 \\
\text { microalbuminuria } \\
\text { and } 316 \text { proteinuria/ } \\
\text { ESRD) and } 646 \text { con- } \\
\text { trols (T2DM-normoal- } \\
\text { buminuria) }\end{array}$ & & & 0.92 & $1.01(0.86-1.19)$ \\
\hline & Pezzolesi et al. [51] & Caucasian & $\begin{array}{l}382 \text { controls (non } \\
\text { T2DM) and } 416 \text { cases } \\
\text { (T2DM- DKD) }\end{array}$ & & & 0.0014 & $N A^{d}$ \\
\hline
\end{tabular}


Table 1 continued

\begin{tabular}{|c|c|c|c|c|c|c|c|}
\hline Variant & Reference & Ethnicity & Sample description & $\begin{array}{l}\text { Chromossome } 9^{a} \\
\text { position }\end{array}$ & Risk allele & $P$ value & Odds ratio $(95 \% \mathrm{Cl})$ \\
\hline & Moyaart et al. [29] & Caucasian & $\begin{array}{l}\text { Meta-analysis } \\
1052 \text { cases (DKD) } \\
2057 \text { controls (T1DM) }\end{array}$ & & & 0.60 & $0.74(0.65-0.83)$ \\
\hline \multirow[t]{10}{*}{ rs10868025 } & Pezzolesi et al. [25] & Caucasian & & 86164176 & A & 0.00005 & $1.45(1.25-1.67)$ \\
\hline & Williams et al. [30] & Caucasian & & & & 0.19 & $1.06(0.97-1.17)$ \\
\hline & Pezzolesi et al. [51] & Caucasian & & & & 0.0039 & $N A^{e}$ \\
\hline & Pezzolesi et al. [58] & Caucasian & & & & 0.90 & $0.99(0.84-1.16)$ \\
\hline & Maeda et al. [26] & Japanese & $\begin{array}{l}754 \text { cases (T2DM-DKD } \\
\text { and retinopathy) and } \\
558 \text { controls (T2DM- } \\
\text { only retinopathy) }\end{array}$ & & & 0.31 & $1.12(0.89-1.42)$ \\
\hline & & & $\begin{array}{l}449 \text { cases (T2DM-DKD } \\
\text { and retinopathy) and } \\
965 \text { controls (T2DM- } \\
\text { only retinopathy) }\end{array}$ & & & 0.54 & $0.94(0.78-1.14)$ \\
\hline & & & $\begin{array}{l}32 \text { cases (T2DM- } \\
\text { microalbuminuria } \\
\text { progressed to overt } \\
\text { proteinuria) and } 168 \\
\text { controls (T2DM- } \\
\text { microalbuminuria) }\end{array}$ & & & 0.07 & $0.49(0.22-1.06)$ \\
\hline & & & $\begin{array}{l}300 \text { cases (T2DM-DKD) } \\
\text { and } 224 \text { controls } \\
\text { (normoalbuminuria } \\
\text { and }>10 \text { years T2DM) }\end{array}$ & & & 0.33 & $0.85(0.62-1.18)$ \\
\hline & Hu et al. [53] & Chinese & & & & 0.25 & $0.91(0.76-1.07)$ \\
\hline & Moyaart et al. [29] & Caucasian & & & & 0.12 & $0.72(0.64-0.81)$ \\
\hline rs13289150 & Pezzolesi et al. [25] & Caucasian & & 83549513 & A & 0.05 & $N A^{c}$ \\
\hline
\end{tabular}

NA not applicable, T2DM type 2 diabetes mellitus, T1DM type 1 diabetes mellitus, DKD diabetes kidney disease, ESRD end-stage renal disease

a Adapted from on the hg19 genome assembly

b Hazard ratio 1.33

c Hazard ratio 1.23

d Z score 3.19

e $Z$ score 2.88

Recently, a GWAS was performed by Palmer et al. [57] with the objective of evaluating candidate DKD susceptibility genes in African Americans. The SNPs selected were the same previously studied in European ancestries by Pezzolesi et al. [25]. The results showed that SNPs in FRMD3 tended toward association with T2DM-ESRD $(\mathrm{P}<0.05)$.

\section{Conclusions}

Even though not much is known about the FRMD3 gene, some studies provide insights into the relationship between FRMD3 variants and DKD. Major findings in the African American population show an association between DKD and many SNPs, especially rs 10867977 (OR 1.31, 95 \% CI 1.06-1.62). In the Japanese population, a significant association was found only at rs1888747, whereas in Caucasians three SNPs have been found to be associated with DKD (rs1888746, rs1888747, rs10868025). Nevertheless, considering all SNPs and ethnic groups analyzed, the strongest association was found in Caucasians with polymorphisms rs1888747 and rs10868025. However, the data produced so far is not sufficient to ascertain a role of FRMD3 in DKD pathogenesis. Also, because the relationship between the FRMD3 gene and DKD was recently detected, very few studies focusing on its mRNA and protein expression are available. Some limitations regarding the development of genetic association studies for diabetic complications could explain differences among studies which evaluated the FRMD3 gene. The first limitation involves differences in the definition of DKD among the studies. The recommended prognosis of DKD is determined by two parameters, GFR and albuminuria levels. Nevertheless, the majority of studies frequently use only one of these 
parameters to classify the disease. Moreover, differences in confounding factors such as DM duration and glycemic control could also influence the results.

The functional context of FRMD3 could be experimentally elucidated by several approaches. One possibility is to perform functional studies in kidney cells to evaluate the consequences of FRMD3 gene silencing/ overexpression. Knockout/transgenic mouse models may also contribute to clarify FRMD3 function in the kidney. Fine mapping studies of GWAS data could identify new functional FRMD3 polymorphisms associated with DKD. Moreover, designing studies would be helpful to determine what molecules could be interacting with FRMD3 aiming to further increase knowledge of the mechanisms and pathways in which the gene is involved and its relation to diseases, as suggested by Martini et al. [50].

In summary, FRMD3 is a strong candidate gene for DKD. However, further studies are needed to explain the pathways through which FRMD3 influences the onset of this diabetic complication.

\begin{abstract}
Abbreviations
DKD: diabetic kidney disease; GWAS: genome wide association studies; SNPS: single nucleotide polymorphisms; DM: diabetes mellitus; CKD: chronic kidney disease; ESRD: end-stage renal disease; UAE: urinary albumin excretion; ADA: American diabetes association; eGFR: estimated GFR;T1DM: type 1 diabetes; EURODIAB: the European diabetes prospective complications study; FRMD3: 4.1 protein ezrin, radixin, moesin [FERM] domain containing 3; T2DM: type 2 diabetes mellitus; TFBS: transcription factor binding site; BMP: bone morphogenetic protein; GoKinD: genetics of kidneys in diabetes; JDC: joslin diabetes center; GWU: George Washington university; DCCT/EDIC: diabetes control and complications trial/epidemiology of diabetes interventions and complications; APOL1: apolipoprotein L1; MYH9: non-muscle myosin heavy chain 9; GENIE: Genetics of nephropathy - an international effort; UK-ROI: Republic of Ireland; FinnDiane: finnish DKD study; HOMF: homeodomain factor.
\end{abstract}

\section{Authors' contributions}

MPB wrote the manuscript; DAS reviewed the manuscript and contributed to the discussion; FG reviewed the manuscript and contributed to the discussion; DC reviewed the manuscript and contributed to the discussion; LHC reviewed the manuscript and contributed to the discussion. All authors read and approved the final manuscript.

\section{Author details \\ ${ }^{1}$ Endocrine Division, Hospital de Clínicas de Porto Alegre, Federal University of Rio Grande do Sul, Rua Ramiro Barcelos 2350, prédio 12, $4^{\circ}$ andar, Porto Alegre, RS 90035-003, Brazil. ${ }^{2}$ Endocrinology, Federal University of Rio Grande do Sul, Porto Alegre, RS, Brazil. ${ }^{3}$ Federal University of Rio Grande do Sul, Porto Alegre, RS, Brazil.}

\section{Acknowledgements}

This study was partially supported by grants from the Conselho Nacional de Desenvolvimento Científico e Tecnológico (CNPq), Fundação de Amparo à Pesquisa do Rio Grande do Sul (FAPERGS) and Fundo de Incentivo à Pesquisa e Eventos (FIFE) at Hospital de Clínicas de Porto Alegre.

Grant support Conselho Nacional de Desenvolvimento Científico e Tecnológico (CNPq), Fundação de Amparo à Pesquisa do Rio Grande do Sul (FAPERGS) and Fundo de Incentivo à Pesquisa (FIPE) from Hospital de Clínicas de Porto Alegre.

\section{Competing interests}

All the authors declared no competing interests.
Received: 25 July 2015 Accepted: 19 December 2015

Published online: 30 December 2015

\section{References}

1. Association AD. Standards of medical care in diabetes-2014. Diabetes Care. 2014;37(Suppl 1):S14-80.

2. Association AD. Standards of medical care in diabetes: summary of revisions. Diabetes Care. 2015;38(Suppl):S4.

3. Sortica DA, et al. The role of ecto-nucleotide pyrophosphatase/phosphodiesterase 1 in diabetic nephropathy. Arq Bras Endocrinol Metabol. 2011;55(9):677-85.

4. Levey AS, et al. Definition and classification of chronic kidney disease: a position statement from Kidney Disease: improving Global Outcomes (KDIGO). Kidney Int. 2005;67(6):2089-100.

5. Bloomgarden ZT. Diabetic nephropathy. Diabetes Care. 2008;31(4):823-7.

6. Bruno RM, Gross JL. Prognostic factors in Brazilian diabetic patients starting dialysis: a 3.6-year follow-up study. J Diabetes Compl. 2000;14(5):266-71.

7. de Boer $\mathbb{H}$ et al. Temporal trends in the prevalence of diabetic kidney disease in the United States. JAMA. 305(24):2532-9

8. Dwyer JP et al. Renal dysfunction in the presence of normoalbuminuria in type 2 diabetes: results from the DEMAND Study. Cardiorenal Med. 2(1): 1-10.

9. Kramer H. Screening for kidney disease in adults with diabetes and prediabetes. Curr Opin Nephrol Hypertens. 2005;14(3):249-52.

10. Kramer CK, et al. Clinical and laboratory profile of patients with type 2 diabetes with low glomerular filtration rate and normoalbuminuria. Diabetes Care. 2007;30(8):1998-2000.

11. Ada ADA. Standards of medical care in diabetes-2006. Diabetes Care. 2006;29(Suppl 1):S4-42.

12. ADA. Standards of medical care in diabetes-2013. Diabetes Care. 36(Suppl 1): S11-66.

13. Stevens PE, Levin A. Evaluation and management of chronic kidney disease: synopsis of the kidney disease: improving global outcomes 2012 clinical practice guideline. Ann Intern Med. 2013;158(11):825-30

14. KDIGO. clinical practice guideline for the evaluation and management of chronic kidney disease. Kidney Int. 2012; Suppl: S1-S150.

15. Chaturvedi $\mathrm{N}$, et al. Microalbuminuria in type 1 diabetes: rates, risk factors and glycemic threshold. Kidney Int. 2001;60(1):219-27.

16. Adler Al, et al. Development and progression of nephropathy in type 2 diabetes: the United Kingdom Prospective Diabetes Study (UKPDS 64). Kidney Int. 2003;63(1):225-32.

17. Krolewski AS. Genetics of diabetic nephropathy: evidence for major and minor gene effects. Kidney Int. 1999;55(4):1582-96.

18. Caramori ML, Fioretto P, Mauer M. The need for early predictors of diabetic nephropathy risk: is albumin excretion rate sufficient? Diabetes. 2000:49(9): 1399-408.

19. Perkins $B A$, et al. Regression of microalbuminuria in type 1 diabetes. $\mathrm{N}$ Engl J Med. 2003;348(23):2285-93.

20. Canani LH, Gerchman F, Gross JL. Familial clustering of diabetic nephropathy in Brazilian type 2 diabetic patients. Diabetes. 1999;48(4):909-13.

21. Yajima Y, Nakajima S. Familial clustering and genetics of diabetic nephropathy. Nihon Rinsho. 1997;55(Suppl):795-801.

22. Martini $\mathrm{S}$, et al. Defining human diabetic nephropathy on the molecular level: integration of transcriptomic profiles with biological knowledge. Rev Endocr Metab Disord. 2008;9(4):267-74.

23. Pezzolesi MG, Krolewski AS. Diabetic nephropathy: is ESRD its only heritable phenotype? J Am Soc Nephrol. 2013;24(10):1505-7.

24. Pezzolesi MG, Krolewski AS. The genetic risk of kidney disease in type 2 diabetes. Med Clin North Am. 2013;97(1):91-107.

25. Pezzolesi MG, et al. Genome-wide association scan for diabetic nephropathy susceptibility genes in type 1 diabetes. Diabetes. 2009;58(6):1403-10

26. Maeda S, et al. Replication study for the association between four Loci identified by a genome-wide association study on European American subjects with type 1 diabetes and susceptibility to diabetic nephropathy in Japanese subjects with type 2 diabetes. Diabetes. 2010;59(8):2075-9. 
27. Ng DP, Krolewski AS. Molecular genetic approaches for studying the etiology of diabetic nephropathy. Curr Mol Med. 2005;5(5):509-25

28. Freedman BI, et al. Genetic factors in diabetic nephropathy. Clin J Am Soc Nephrol. 2007;2(6):1306-16.

29. Mooyaart AL, et al. Genetic associations in diabetic nephropathy: a metaanalysis. Diabetologia. 2011;54(3):544-53.

30. Williams WW, et al. Association testing of previously reported variants in a large case-control meta-analysis of diabetic nephropathy. Diabetes. 2012;61(8):2187-94.

31. Lohmueller KE, et al. Meta-analysis of genetic association studies supports a contribution of common variants to susceptibility to common disease. Nat Genet. 2003;33(2):177-82.

32. Carpena MP, et al. Genetics of diabetic nephropathy. Arq Bras Endocrinol Metabol. 2010;54(3):253-61.

33. Zeggini E, loannidis JP. Meta-analysis in genome-wide association studies. Pharmacogenomics. 2009;10(2):191-201.

34. McKnight AJ, McKay V, Maxwell AP. Genetic and epigenetic risk factors for diabetic kidney disease. Adv Chronic Kidney Dis. 21(3): 287-96.

35. $\mathrm{Ni}$ X, et al. Molecular cloning and characterization of the protein 4.10 gene, a novel member of the protein 4.1 family with focal expression in ovary. J Hum Genet. 2003;48(2):101-6.

36. Hoover KB, Bryant PJ. The genetics of the protein 4.1 family: organizers of the membrane and cytoskeleton. Curr Opin Cell Biol. 2000;12(2):229-34.

37. Ramez M, et al. Distinct distribution of specific members of protein 4.1 gene family in the mouse nephron. Kidney Int. 2003;63(4):1321-37.

38. Chishti AH, et al. The FERM domain: a unique module involved in the linkage of cytoplasmic proteins to the membrane. Trends Biochem Sci. 1998;23(8):281-2.

39. Baines AJ. A FERM-adjacent (FA) region defines a subset of the 4.1 superfamily and is a potential regulator of FERM domain function. BMC Genom. 2006;7:85.

40. Takakuwa Y. Protein 4.1, a multifunctional protein of the erythrocyte membrane skeleton: structure and functions in erythrocytes and nonerythroid cells. Int J Hematol. 2000;72(3):298-309.

41. Pasternack GR, et al. Interactions between protein 4.1 and band 3. An alternative binding site for an element of the membrane skeleton. J Biol Chem. 1985;260(6):3676-83.

42. Lombardo CR, Willardson BM, Low PS. Localization of the protein 4.1-binding site on the cytoplasmic domain of erythrocyte membrane band 3. J Biol Chem. 1992;267(14):9540-6.

43. Marfatia SM, et al. Identification of the protein 4.1 binding interface on glycophorin C and p55, a homologue of the Drosophila discs-large tumor suppressor protein. J Biol Chem. 1995;270(2):715-9.
44. Nunomura W, et al. Regulation of CD44-protein 4.1 interaction by Ca2+ and calmodulin. Implications for modulation of CD44-ankyrin interaction. J Biol Chem. 1997;272(48):30322-8.

45. Schischmanoff PO, et al. Defining of the minimal domain of protein 4.1 involved in spectrin-actin binding. J Biol Chem. 1995;270(36):21243-50.

46. Walensky LD, et al. The 13-kD FK506 binding protein, FKBP13, interacts with a novel homologue of the erythrocyte membrane cytoskeletal protein 4.1. J Cell Biol. 1998;141(1):143-53.

47. Mattagajasingh SN, et al. A nonerythroid isoform of protein 4.1R interacts with the nuclear mitotic apparatus (NuMA) protein. J Cell Biol. 1999;145(1):29-43.

48. Kramer-Zucker AG, et al. Organization of the pronephric filtration apparatus in zebrafish requires Nephrin, Podocin and the FERM domain protein Mosaic eyes. Dev Biol. 2005;285(2):316-29.

49. Wei $X$, et al. Kindlin-2 regulates renal tubular cell plasticity by activation of Ras and its downstream signaling. Am J Physiol Renal Physiol. 2013;306(2):F271-8.

50. Martini $\mathrm{S}$, et al. From single nucleotide polymorphism to transcriptional mechanism: a model for FRMD3 in diabetic nephropathy. Diabetes. 2013;62(7):2605-12

51. Pezzolesi MG, et al. Family-based association analysis confirms the role of the chromosome 9 q21.32 locus in the susceptibility of diabetic nephropathy. PLoS One. 2013;8(3):e60301.

52. Dolan V, Hensey C, Brady HR. Diabetic nephropathy: renal development gone awry? Pediatr Nephrol. 2003;18(2):75-84.

53. Hu C, et al. CPVL/CHN2 genetic variant is associated with diabetic retinopathy in Chinese type 2 diabetic patients. Diabetes. 2011;60(11):3085-9.

54. Palmer ND, Freedman BI. Diabetic nephropathy: FRMD3 in diabetic nephropathy-guilt by association. Nat Rev Nephrol. 2013;9(6):313-4

55. Freedman $\mathrm{Bl}$, et al. Differential effects of $\mathrm{MYH} 9$ and $A P O L 1$ risk variants on FRMD3 Association with Diabetic ESRD in African Americans. PLoS Genet. 2011;7(6):e1002150.

56. Park $\mathrm{H}$, et al. A family-based association study after genome-wide linkage analysis identified two genetic loci for renal function in a Mongolian population. Kidney Int. 2013;83(2):285-92.

57. Palmer ND, et al. Evaluation of candidate nephropathy susceptibility genes in a genome-wide association study of African American diabetic kidney disease. PLoS One. 2014;9(2):e88273.

58. Pezzolesi, M.G., et al., An intergenic region on chromosome $13 q 33.3$ is associated with the susceptibility to kidney disease in type 1 and 2 diabetes. Kidney Int. 80(1): 105-11.

\section{Submit your next manuscript to BioMed Central and we will help you at every step:}

- We accept pre-submission inquiries

- Our selector tool helps you to find the most relevant journal

- We provide round the clock customer support

- Convenient online submission

- Thorough peer review

- Inclusion in PubMed and all major indexing services

- Maximum visibility for your research

Submit your manuscript at www.biomedcentral.com/submit
() Biomed Central 